\title{
Analysis of the Composition and Physical and Mechanical Properties of Raw Materials for Thermal Insulation Fabrics
}

\author{
Juramirza Abdiramatovich Kayumov¹, Matluba Nazarova², Bohodir Vohobjon Ogli Obilov, \\ Farhodjon Mahmudjonovich Dadaboyev², Zuhra Yigitaliyevna Mamadaliyeva ${ }^{2}$ \\ ${ }^{1}$ College of Textile Science and Engineering (International Institute of Silk), Zhejiang Sci-Tech University, Hangzhou, China \\ ${ }^{2}$ Faculty of Technology of Light Industry, Namangan Institute of Engineering and Technology, Namangan, Uzbekistan \\ Email: juramirza@zstu.edu.cn, matluba.nazarova91@gmail.com,obilov_b93@mail.ru, farhodjon1975@bk.ru, \\ zuhramamadaliyeva@mail.ru
}

How to cite this paper: Kayumov, J.A., Nazarova, M., Obilov, B.V.O., Dadaboyev, F.M. and Mamadaliyeva, Z.Y. (2021) Analysis of the Composition and Physical and Mechanical Properties of Raw Materials for Thermal Insulation Fabrics. Engineering, 13, 352-359.

https://doi.org/10.4236/eng.2021.136025

Received: April 13, 2021

Accepted: June 27, 2021

Published: June 30, 2021

Copyright $\odot 2021$ by author(s) and Scientific Research Publishing Inc. This work is licensed under the Creative Commons Attribution International License (CC BY 4.0).

http://creativecommons.org/licenses/by/4.0/ (c) (i) Open Access

\begin{abstract}
In this article, winter clothes, bedding, pillows, mattresses are produced in the Republic of Uzbekistan and used in the export products of foreign countries in domestic market shopping centers; existing nonwoven fabric samples were used as toys, children's clothing as a heat retainer, a space-filler was selected on the basis of marketing survey analysis. Chemical bonding, processing technology, methods, linear density, thickness, air permeability, hygroscopicity, heat storage and heat transfer properties of the samples were analyzed experimentally based on the preparation methods, the fiber content was compared with the standard technology. The advantages and disadvantages of the samples were studied and recommendations for use in sewing according to consumer requirements were given.
\end{abstract}

\section{Keywords}

Sintepon (Origin Polyester Fiber), Sherstepon (Origin Wool + Polyester Fiber), Hollow Fiber, Polyester, Nitron, Insulation Fabrics

\section{Introduction}

As a result of the use of cotton fiber, natural silk, as well as a large number of chemical yarns in the textile and light industry of the Republic of Uzbekistan, the range of products produced in these industries is growing from year to year. The needs of textile and light industry enterprises of the Uzbekistan in chemical yarns and fibers are met by Fergana acetate and nylon fibers, Navoi (nitron fiber) chemical fiber enterprises and imported chemical yarns and fibers (viscose, 
lavsan, kapron). The share of textile fibers consumed worldwide is given in the table (Table 1) [1].

According to the results in the table, in 2020-2030 it can be seen that chemical fibers occupy $90 \%-92 \%$ of all fibers used in textiles, i.e. the maximum amount. A variety of synthetic polymers are used in the production of chemical fibers, and the change in the properties of the fibers depends on the physical and chemical changes of the polymers. It is possible to obtain fibers of different properties based on the technology of production of synthetic fibers from the polymer obtained by processing monomers [2] [3].

Chemical fibers are increasingly being produced and widely used due to their low cost and quality (mechanical properties: strength, elasticity, abrasion resistance, permeability) compared to natural fibers. In particular, scientists who create innovative materials have offered new features of nonwovens to the textile industry by mixing natural fibers into synthetic polymers. An example of such a material is a heat-insulating fabric made on the basis of polyester [4] [5].

The use of space-filling details in clothing, bedding, pillows, mattresses, toys, children's clothing for the winter season is always in demand.

The range of non-woven materials is diverse in terms of production method, raw materials used and decoration. According to the fiber content, it is divided into cotton, semi-wool, silk (made of chemical fibers and yarns) and linen. According to the purpose of use, non-woven materials are divided into household and technical types.

The range of outerwear for the autumn-winter season includes a variety of processes and technologies for the production of raw materials used in garments made of plaid fabric, heat-retaining intermediate details.

As a result of the development of small business and private entrepreneurship in Uzbekistan, the facilities created in the industry, the ongoing reforms, our domestic market and export potential are growing. In the manufacture of industrial products, the use of recycled, low-cost raw materials produced by foreign countries is growing: plastic containers and heat-insulating non-woven fabrics from waste oil (Figure 1).

Due to the fact that this non-woven fabric is made of $100 \%$ synthetic (polyester) fibers, it has been found to cause diseases that adversely affect human health (various allergies, cancer) [4]. Therefore, the range of existing enterprises for the production of heat-insulating nonwovens in Uzbekistan was analysed and aimed at improving the natural properties of fabrics.
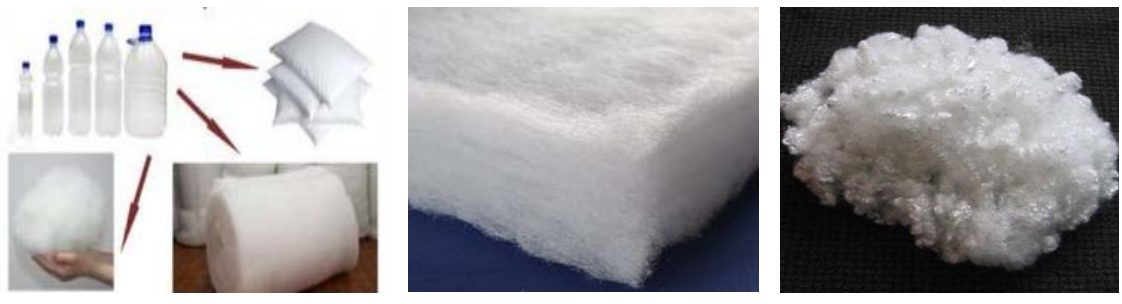

Figure 1. Heat-insulating nonwovens. 
Table 1. The share of textile fibers consumed worldwide, $\%$.

\begin{tabular}{cccc}
\hline \multirow{2}{*}{ Years } & \multicolumn{3}{c}{ Fibers } \\
\cline { 2 - 4 } & Cotton & Wool and silk fibers & Chemical fibers \\
\hline 1960 & 68 & 9 & 23 \\
1970 & 53 & 8 & 39 \\
1980 & 35 & 5 & 60 \\
2000 & 12 & 2 & 86 \\
$2020-2030$ & $6-7$ & 2 & $90-92$ \\
\hline
\end{tabular}

\section{Marketing Studies}

Along with the increase in the range of products in the production of modern garments, the level of demand for the design of products, raw materials used in clothing, their composition plays an important role. The marketing analyses were conducted in the domestic markets of the Uzbekistan, in particular, in the autumn-winter season of garments and outerwear, to study the quality of products, consumer demand and the level of compliance of garments with the standard (Figure 2).

According to the results of the analysis, the use of interstitial and heat-retaining fabrics in children's and adult garments in Uzbekistan is higher in winter outerwear.

Clothing is in direct contact with the human body, the quality of which is taken into account in the design of the product, is ensured during production and is manifested during operation. Therefore, the fiber composition of clothing and the type of raw material used, the physical properties of the fabric are important. The fibers used for winter clothing must have high heat retention properties. This is because the hygienic properties of fibers depend on their chemical composition and structure [5] [6].

\section{Experimental Methods}

For the study, samples of 3 different types of heat-insulating fabrics with the trademark sintepon, hollowfiber, syntevatin, prepared by the production methods of Russia, China and Ukraine, were selected. The chemical composition was analyzed in the laboratory of the Department of Chemical Technology of the Tashkent Institute of Textile and Light Industry (Figure 3).

To determine the fiber content of the fabrics, $1.00 \mathrm{~g}$ of samples were weighed on an electronic scale (Shinko GS). Samples were placed in numbered glass flasks, $40 \%$ alkaline $\mathrm{NaOH}$ was poured into the flask and boiled at $100^{\circ} \mathrm{C}-120^{\circ} \mathrm{C}$. As a result of the experiment, the sample melted and a precipitate formed. The results of the experimental analysis are shown in Table 2.

The density, air permeability, thickness, hygroscopicity, and thermal storage properties of the fabric were analyzed, taking into account that heat-retaining fabrics were mainly used as an intermediate detail of clothing. 


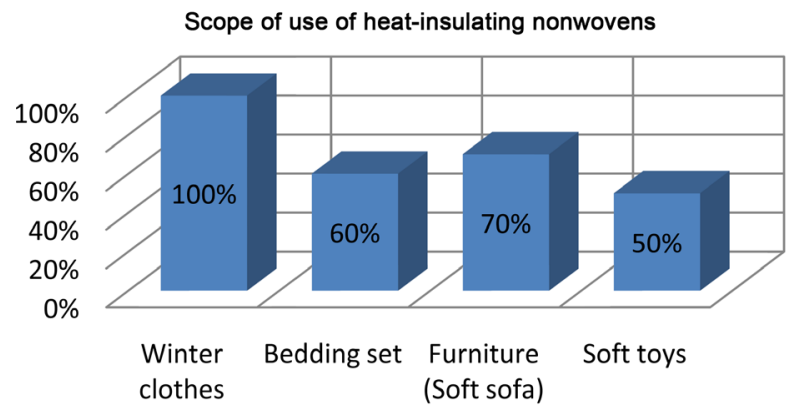

Figure 2. Scope of use of heat-insulating nonwovens.

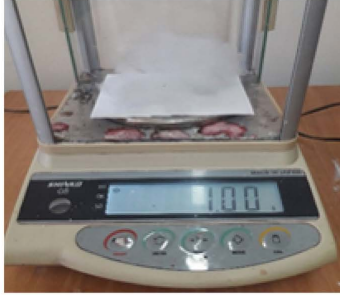

(a)

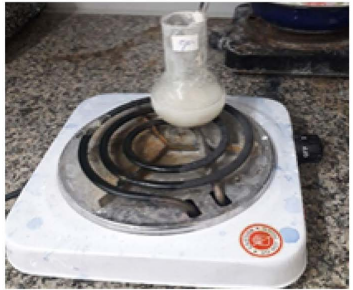

(c)

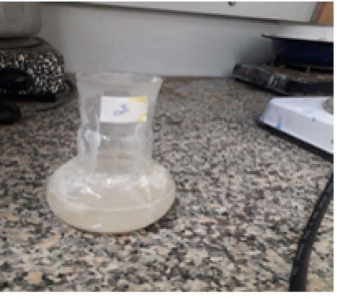

(b)

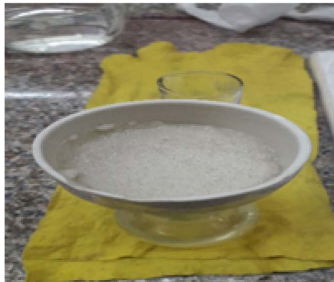

(d)

Figure 3. Experiments to determine the physical-mechanical properties of synthetic fibers using as heat layer of clothing.

Table 2. Experimental analysis of the determination of the fiber content of synthetic fibers by the methods of manufacturing enterprises.

\begin{tabular}{ccccccccc}
\hline & & \multicolumn{3}{c}{ Fiber content } & \multicolumn{3}{c}{ Binder } & \multicolumn{2}{c}{$\begin{array}{c}\text { The difference } \\
\text { between the fibers }\end{array}$} \\
\cline { 3 - 8 } & $\begin{array}{c}\text { Sample } \\
\text { name }\end{array}$ & Name & $\begin{array}{c}\text { Quantity } \\
(\%)\end{array}$ & Name & $\begin{array}{c}\text { Fiber } \\
\text { content }\end{array}$ & $\begin{array}{c}\text { Quantity } \\
(\%)\end{array}$ & $\begin{array}{c}\text { Diameter } \\
(\mathrm{mkr})\end{array}$ & $\begin{array}{c}\text { Length } \\
(\mathrm{Mm})\end{array}$ \\
\hline 1 & Sintepon & PET & 92 & LMF & PET & 8 & 6 & $49-100$ \\
2 & Hollowfiber & PET & 92 & LMF & PET & 8 & $1,2-3$ & 38 \\
3 & Syntovatin & PET & 92 & LMF & PET & 8 & 3 & 64 \\
\hline
\end{tabular}

Three samples of size $100 \times 100 \mathrm{~mm}$ were cut to determine the surface density of $120 \mathrm{~mm}$ to $200 \mathrm{~mm}$ thick fabrics of the same composition selected. GX-400 was detected on a special scale (Table 3 ).

According to the results of the analysis, the 1st sample ranged from 188.5 $\mathrm{gr} / \mathrm{m}^{2}$ to $216 \mathrm{gr} / \mathrm{m}^{2}$, the 2 nd sample ranged from $155.5 \mathrm{gr} / \mathrm{m}^{2}$ to $178.7 \mathrm{gr} / \mathrm{m}^{2}$, the 3rd sample ranged from $168.7 \mathrm{gr} / \mathrm{m}^{2}$ to $196.3 \mathrm{gr} / \mathrm{m}^{2}$. The highest change was noted in Sample 1. 
Table 3. Surface density of samples.

\begin{tabular}{ccccc}
\hline \multirow{2}{*}{$\mathrm{N}^{\circ}$} & Sample & \multicolumn{3}{c}{ Unit of measurement $\left(\mathrm{gr} / \mathrm{m}^{2}\right)$} \\
\cline { 3 - 5 } & & $\mathrm{I}$ & $\mathrm{II}$ & III \\
\hline 1 & Sintepon & 188.5 & 194.2 & 216.1 \\
2 & Hollowfiber & 155.5 & 165.3 & 178.7 \\
3 & Syntovatin & 168.7 & 176.5 & 196.3 \\
\hline
\end{tabular}

Air permeability is the air permeability of a fabric, which depends on its fiber content, density and texture. Rarely woven fabrics have good air permeability, densely woven fabrics, impregnated with water-repellent solutions; rubberized fabrics do not conduct air at all or have low permeability [5]. In addition to the surface density, the thickness of the fabric used in outerwear is important for air permeability. To start the test on the AR-360, the water level in the container, inclined and vertical pressure was checked, a round hole with an area of $16 \mathrm{~cm}^{2}$ was inserted on the exchange table and $160 \times 160$ samples were prepared. The fabric samples were then placed on a vacuum chamber and pressed with a clamp. When the device was started and the hydrostatic pressure approached $12.7 \mathrm{~mm} \cdot \mathrm{Hg}$, the process was stopped and the readings on the vertical manometer indicating the hydrostatic pressure were tabulated (Table 4).

According to the results of the analysis, the air permeability of Sample 3 is higher than other Samples (Table 4, Figure 4).

The disadvantage of synthetic fiber heat-insulating fabrics is that the fabric has low air permeability due to the fact that it is a chemical fiber with the same composition. In addition, the disadvantages of non-woven are: overheating of the body in clothing; problems with sweating; accumulation of static electricity; the raw material is deformed under the influence of high temperatures near heaters or open flames [5] [7] [8].

The hygroscopicity of fabrics determines the nature of wet swelling from the environment (air). In assessing the hygroscopic properties of textile materials, their true moisture characteristics are often used. Yarn fabrics, natural silk fabrics, as well as viscose fabrics have good hygroscopic properties [5] [9]. However, the hygroscopic properties of synthetic fiber fabrics are low. The hygroscopicity of thermal insulation fabrics was checked in accordance with GOST-3816 [10]. This standard defines the methods for determining the hygroscopic and waterproof properties of woven and nonwoven fabrics from all types of fibers and yarns, defined by the following Formula (1) and the results are given in Table 5 .

$$
H=\frac{m_{w}-m_{d}}{m_{d}} \cdot 100(\%)
$$

Here:

$m_{w}$ is the wetted mass of the elementary sample, g;

$m_{d}$ is the mass of the elemental sample after drying, $\mathrm{g}$. 
It is necessary to take into account the properties of the fabric in the creation and design of clothing models. The heat-retaining properties of fabrics are especially important for winter clothing fabrics. These properties depend on the fiber content and thickness of the fabric [5] [7].

The samples were analyzed to study the thermal conductivity and heat storage properties of the samples using the AW-2 device. Before starting the test, the heaters of the appliance were warmed to 36.6 degrees. The test lasted 4 hours for each sample: 2 hours without sample and 2 hours with sample. Climatic conditions in the room during the inspection: temperature $22^{\circ} \mathrm{C}$, humidity $65 \%$. Thermal conductivity and heat storage properties defined by the Formula (2) and the results are given in Table 6:

$$
\left(1-\frac{b}{a}\right) \cdot 100 \% \text {; }
$$

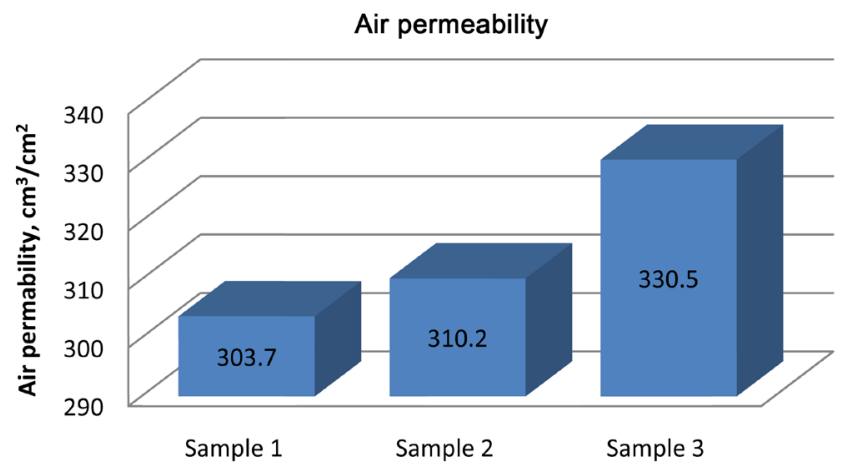

Figure 4. Air permeability of samples.

Table 4. Air permeability.

\begin{tabular}{|c|c|c|c|c|c|}
\hline \multirow{2}{*}{$\mathrm{N}^{\circ}$} & \multirow{2}{*}{ Name of indicators } & \multicolumn{3}{|c|}{ Samples } & \multirow{2}{*}{ Device } \\
\hline & & I & II & III & \\
\hline 3 & $\begin{array}{c}\text { Air permeability }\left(\mathrm{cm}^{3} / \mathrm{cm}^{2} \mathrm{sec} \text { at } 20^{\circ} \mathrm{C}, 1\right. \\
\text { Atmospheric) }\end{array}$ & 303.7 & 310.2 & 330.5 & AP-360 SM \\
\hline
\end{tabular}

Table 5. Hygroscopicity of fabrics.

\begin{tabular}{cccc}
\hline $\mathrm{N}^{\circ}$ & $m_{W}(\mathrm{~g})$ & $m_{d}(\mathrm{~g})$ & Results $(\mathrm{g})$ \\
\hline Sample 1 & 1.916 & 1.879 & 1.96 \\
Sample 2 & 1.914 & 1.850 & 3.45 \\
Sample3 & 1.910 & 1.863 & 2.52 \\
\hline
\end{tabular}

Table 6. Thermal conductivity and heat storage properties.

\begin{tabular}{cccccc}
\hline $\mathrm{N}^{\circ}-1$ & Sample 1 & $\mathrm{N}^{\circ}-2$ & Sample 2 & $\mathrm{N}^{\circ}-3$ & Sample 3 \\
\hline$a$ & 2443 & $\mathrm{a}$ & 2444 & $\mathrm{a}$ & 2432 \\
$b$ & 1043 & $\mathrm{~b}$ & 720 & $\mathrm{~b}$ & 1052 \\
$\%$ & 58 & $\%$ & 59 & $\%$ & 55 \\
\hline
\end{tabular}


Here:

a: duration of heaters without sample (sec).

$b$ : duration of heaters with sample (sec).

\section{Conclusions}

In accordance with the Law of the Republic of Uzbekistan "On Technical Regulation" dated May 11, 2016 No. 148, in accordance with the decision of the Cabinet of Ministers on the safety of light industry products, the use of chemicals in excess of permissible concentrations may adversely affect consumer health [11].

Light industrial products are evaluated on the following components of biological and chemical safety:

- Biological properties (hygroscopic, breathable, water resistance, specific surface electrical resistance);

- Maximum allowable release of harmful chemicals in the air and water environment;

- The intensity of the electrostatic field on the surface of the product is determined in the first and second layer materials made of pure wool, wool, synthetic and mixed materials. This figure should not exceed $15 \mathrm{sq} / \mathrm{m}$.

According to the results of the analysis of heat-insulating nonwovens produced at the manufacturing enterprises of the Uzbekistan, it was determined that the 3 types of samples were $100 \%$ chemical fiber with the same composition. These heat-insulating fabrics pass the air permeability index and have a number of harmful properties: body heat in clothing; problems with sweating; accumulation of static electricity; the cost of raw materials is higher than natural analogues; the raw material is deformed under the influence of high temperatures near heaters or open flames. According to Technical Requirement No. 148, taking into account that synthetic fibers make up 30\% of outerwear, it was found that the samples 1 and 2 did not meet the standard requirement. We recommend these fabrics for the furniture and construction industries. Sample 3 can be used for winter clothing because it is close to the specified requirements.

\section{Conflicts of Interest}

The authors declare no conflicts of interest regarding the publication of this paper.

\section{References}

[1] Ismatullaeva, X.Z., Abdullaev, A.Z. and Ismatullaeva, M. (2007) "Special Materials Science" Tashkent "Economy-Finance".

[2] Dahiya, A., Kamath, M.G., Hegde, R.R. and Kannadaguli, M. (2016) Introduction to Nonwovens. http://www.engr.utk.edu/mse/Textiles/Introduction\%20to\%20Nonwovens 0503.ht $\underline{\mathrm{m}}$

[3] Patel, M. and Bhrambhatt, D. (2011) Nonwovens Technology. M. S. University, Vadodara, India. 
[4] Akopov, P.A. and Shkolny, V.N. (2010) Sintepon Description of the Invention to the Patent 27.06. Byul. № 18.

[5] Abbasova, N.G. and Abdullaev 3, A. (1991) Non-Woven Fabrics Used in the Garment Industry. Study Guide. TTESI, Tashkent.

[6] Genzer, M.S. (1978) Mechanical Technology of Non-Woven Fabrics. Light Industry, $M$.

[7] Tixomirov, V.V. (1966) Non-Woven Adhesives. Light Industry, M.

[8] Xamroev, A.L. (1995) Chemical Fiber Production Technology. Uzbekistan, T.

[9] Matmusaev, U.M. and Abdullaev 3, A. (2005) Textile Materials Science. Uzbekistan, Tashkent.

[10] GOST 3816-81 (ISO 811-81) Textile Cloth. Methods of Determination of Hygroscopic and Water-Repellent Properties (with Changes N 1-4).

[11] (2016) Resolution of the Cabinet of Ministers of the Republic of Uzbekistan "On approval of the General Technical Regulation on Safety of Light Industry Products" No. 148 Tashkent. 